\title{
Haemoglobin typing and its variations in Iranian domestic dogs
}

\author{
Nahid Atyabi • Reza Rahbarghazi • Atefeh Araghi • \\ Omid Ali Neqouiejahromi
}

Received: 21 June 2011 / Accepted: 10 August 2011 /Published online: 2 September 2011

(C) The Author(s) 2011. This article is published with open access at Springerlink.com

\begin{abstract}
The study of canine haemoglobin ( $\mathrm{Hb}$ ) components can help to forecast $\mathrm{Hb}$ changes during many pathological and physiological processes such as responsive anaemia. The aims of our study were to show canine $\mathrm{Hb}$ electrophoretic pattern on cellulose acetate and identify $\mathrm{Hb}$ types similar to the human $\mathrm{Hb}$ pattern. Blood samples from 78 different canine breeds were randomly collected in tubes containing anticoagulant EDTA. Animals were brought to the Small Animal Teaching Centre for a check-up and vaccination. All blood samples underwent electrophoresis on cellulose acetate paper strips to determine $\mathrm{Hb}$ types. Haematocrit and $\mathrm{Hb}$ were measured simultaneously. The $\mathrm{Hb}$ electrophoresis results showed that $\mathrm{Hb} \mathrm{A}_{1}$ was assigned to most of $\mathrm{Hb}$ components on cellulose acetate paper. Also, in some blood samples, $\mathrm{Hb} \mathrm{\textrm {A } _ { 2 }}$ was detected at the cathode end of cellulose acetate paper similar to human $\mathrm{Hb} \mathrm{A}_{2}$, by densitometer. Small amounts of $\mathrm{Hb} F$ were detected in some dogs which was not significant. According to our study, $\mathrm{Hb} \mathrm{A}_{1}$ composes most of the total $\mathrm{Hb}$ percent in canine blood. Two types of $\mathrm{Hb}, \mathrm{A}_{2}$ and $\mathrm{F}$, were detected in a few animals, but the majority did not possess $\mathrm{Hb} F$. It seems that $\mathrm{Hb} F$ is not significant in these animals. We concluded that one or two Hb types could be seen in dogs. There is no difference in electrophoretic pattern between male and female dogs.
\end{abstract}

Keywords Electrophoresis · Haemoglobin $\mathrm{A}_{1}$. Haemoglobin $A_{2} \cdot$ Dog $\cdot$ Sex $\cdot$ Breeds

N. Atyabi $(\bowtie) \cdot R$. Rahbarghazi $\cdot$ A. Araghi

O. A. Neqouiejahromi

College of Veterinary Medicine, University of Tehran,

Tehran, Iran

e-mail: natyabi@ut.ac.ir

\section{Introduction}

Red blood cells (RBCs) play the main role in oxygen transportation, which take oxygen from the lungs and deliver it to numerous tissues during circulation. The major constituent of RBCs is haemoglobin $(\mathrm{Hb})$; it has the capacity to bind oxygen and later releases carbon dioxide. In man at rest, about $250 \mathrm{ml}$ of oxygen is used whilst $200 \mathrm{ml}$ of carbon dioxide is produced per minute and therefore highlights the importance of the following topic since $\mathrm{Hb}$ transportation capacity is 100 times more than plasma transportation capacity alone. This molecule is spherical with a molecular weight approximately $64,500 \mathrm{D}$ (Telen 2009). $\mathrm{Hb}$ is a tetrameric protein consisting of four polypeptide globin chains, each of which contains a heme prosthetic group within a hydrophobic pocket. In adults, this molecule consists of two identical alpha and two non-alpha chains that are generally classified as beta chains (Harvey 1997).

In humans, different kinds of $\mathrm{Hb}$ such as $\mathrm{A}_{1}, \mathrm{~A}_{2}, \mathrm{~F}$, Gower I, Gower II and Portland are found depending on age. The globin structure of $\mathrm{A} 1, \mathrm{~A}_{2}$ and $\mathrm{F}$ has molecular structure of $\alpha_{2} \beta_{2}, \alpha_{2} \delta_{2}, \alpha_{2} \gamma_{2}$, respectively. Hb Gower I, Gower II and Portland which dominate during the first 3 months of fetal development are known as embryonic $\mathrm{Hb}$, while fetal $\mathrm{Hb}$ predominates over the production of embryonic $\mathrm{Hb}$ during the early infancy period (Telen 2009). Most animals also synthesize embryonic and fetal $\mathrm{Hb}$ at the embryonic and fetal stages, respectively. In animals, the embryonic globin chain is designated as $\mathrm{Hb} \varepsilon$, like humans. Beta globin chain synthesis is predominant around mid-gestation. At birth, a mixture of adult and fetal $\mathrm{Hb}$ is seen. Soon after birth, the level of $\mathrm{Hb} \mathrm{F}$ decreases, but its synthesis ability in response to anaemia still remains (Kaneko 2000). 
Normal and different variants of Hbs are identified by standard laboratory techniques. Cellulose acetate electrophoresis can detect most variants of $\mathrm{Hb}$ at alkaline $\mathrm{pH}$ as well as isoelectric focusing (IEF) method. Confirmation is done by HPLC, citrate agar and IEF (Telen 2009).

Chickens, albino rats, guinea pigs, rabbits, horses, pigs, dogs and cats all lack fetal $\mathrm{Hb}$. Embryonal $\mathrm{Hb}$ is replaced by adult $\mathrm{Hb}$ during the fetal period. In dogs, fetal $\mathrm{Hb}$ cannot be distinguished from adult $\mathrm{Hb}$ by electrophoretic or peptide mapping. It has been demonstrated that there are one or two types of adult $\mathrm{Hb}$ in dogs. Postulated genetic control for dogs includes designated $\alpha_{2} \varepsilon_{2}$ as embryonic $\mathrm{Hb}$ and $\alpha_{2} \beta_{2}$ for adult $\mathrm{Hb}$. In felines, there are three different types of embryonic $\mathrm{Hb}$ components during 21 days post conception, and 20-30 days post conception, adult $\mathrm{Hb}$ has already emerged (Kitchen and Brett 2006).

The acetate cellulose electrophoresis technique is widely used for detection of serum protein and its quantitation. The biggest advantage of $\mathrm{Hb}$ electrophoresis on acetate cellulose is simplicity. All $\mathrm{Hb}$ types as $\mathrm{A}_{1}, \mathrm{~A}_{2}, \mathrm{~F}$ as well as abnormal $\mathrm{Hb}$ $\mathrm{C}$ and $\mathrm{S}$ are indentified and quantitated (Rosenbaum 1966). Rose et al. demonstrated that impregnation of cellulose acetate with citrate agar would provide $\mathrm{Hb} \mathrm{S}$ and $\mathrm{C}$ separation and haemoglobinopathies associated with them. This method is also an excellent established method for separation of $\mathrm{Hb} \mathrm{A}$ and F (Schneider et al. 1974).

Process simplicity and the absence of adsorption yield a clean white background between fractions. Therefore, there is no adsorptive loss of protein during migration (Bartlett 1963). The existence of large pores in the cellulose acetate membrane provides minimal sieving effect on proteins. Therefore, electrophoretic separation is entirely dependent on charged density of the molecules (Westermeier and Gronau 2005). $\mathrm{Hb}$ molecules have negative net charge in alkaline $\mathrm{pH} 8.6$ and move towards the anode in cellulose acetate electrophoresis. The electrophoretic mobility of $\mathrm{Hb}$ $\mathrm{A}$ is greater than that of $\mathrm{Hb} \mathrm{F}$ and $\mathrm{A}_{2}$, but $\mathrm{Hb} \mathrm{A}_{2}$ is not far from the cathode, and $\mathrm{Hb} \mathrm{F}$ is located between them (Elghetany 2007). The aims of this study were to assess canine $\mathrm{Hb}$ components by cellulose acetate electrophoresis and to detect different types of canine $\mathrm{Hb}$.

\section{Materials and methods}

Blood samples were collected randomly from 78 different canine breeds (41 male and 37 female) which were presented for check-up and vaccination to the Small Animal Teaching Hospital in the College of Veterinary Medicine, University of Tehran, during the 6-month period from November 2009.

The dogs had no suspected clinical symptoms and were from different breeds such as bulldog, Chihuahua, Doberman,
German shepherd, Great Dane, mixed breed, Pekingese, Poodles, Shih Tzu and Terrier (data shown in Table 1). All blood samples were electrophorized at room temperature $\left(25^{\circ} \mathrm{C}\right)$. Haematocrit $(\mathrm{Hct})$ and $\mathrm{Hb}$ levels were determined prior to electrophoresis by a haematologic analyzer (HemaScreen 18, HOSPITEX DIAGNOSTICS, Sesto Fiorentino, Italy). Other information and data such as sex, breed and age were also recorded. To produce the $\mathrm{Hb}$ haemolysate, whole blood samples were collected in microcentrifuge tubes containing the anticoagulant EDTA, centrifuged for $10 \mathrm{~min}$ at $2.3 \mathrm{~g}(5,000 / \mathrm{rpm})$ to provide RBC pellet and washed three times with saline. After centrifugation, the washed RBCs were suspended in equal volume of saline. In the following process, $100 \mu \mathrm{L}$ of haemolysate reagent (Cellogel Electrophoresis Co., Milan, Italy) was added to $20 \mu \mathrm{L}$ RBC pellet and shaken vigorously for 5-7 $\mathrm{min}$ to lyse all cells to produce a clear red-coloured solution. Then the lysate was centrifuged to obtain the supernatant which was discarded. The Cellogel/Myl cellulose acetate paper (Cellogel Electrophoresis Co., Milan, Italy) strips were soaked in Tris glycine buffer solution (Cellogel Electrophoresis Co., Milan, Italy) for $15 \mathrm{~min}$ as per manufacturer's instruction. In the next step, $10 \mu \mathrm{L}$ of the centrifuged pellet was loaded onto the cellulose acetate paper using an applicator, and electrophoresis was for between 30 and $40 \mathrm{~min}$ at $250 \mathrm{~V}$ and $7 \mathrm{~mA}$. After electrophoresis, the paper was stained with Amido black (Cellogel Electrophoresis Co., Milan, Italy) for $7 \mathrm{~min}$ and then washed roughly three times for $5 \mathrm{~min}$ for each turn in destaining solution (Cellogel Electrophoresis Co., Milan, Italy). The strips were cleared in clearing solution (Cellogel Electrophoresis Co., Milan, Italy) for $5 \mathrm{~min}$ and dried in an oven at $70^{\circ} \mathrm{C}$ for $20 \mathrm{~min}$. The strips were analysed by densitometer and using PhotoEP V7.51XP software (Bender $\&$ Hobein $\mathrm{GmbH}$, Munchen, Germany). In addition, several human male blood samples were used to compare $\mathrm{Hb}$ running pattern on cellulose acetate paper.

\section{Results}

In the present study, $\mathrm{Hb}$ electrophoresis was done on cellulose acetate paper. There were no differences between female and male $\mathrm{Hb}$ electrophoresis pattern on macroscopic view (Fig. 1), and no difference was found according to age. The greatest $\mathrm{Hb}$ components were at the anode end in the same line approximately, but in some cases at cathode side, low values of $\mathrm{Hb} \mathrm{A} \mathrm{A}_{2}$ were also observed by densitometer analysis (Fig. 3, c and d). The human $\mathrm{Hb}$ moved faster than canine species (Fig. 2). According to this study, distribution of the levels of $\mathrm{Hb}$ was normal, and no statistically significant difference was observed between males and females ( $t$ test, $P=0.939$ ) (Table 2). Hct distribution was normal and similar to $\mathrm{Hb}$. Hct distribution for all samples was 
Table 1 Distribution of descriptive characteristics of the 78 dogs that underwent blood sampling for cellulose acetate electrophoresis at the Veterinary School, Small Animal Teaching Hospital, University of Tehran

\begin{tabular}{clcccc}
\hline Breed & & Frequency $(\%)$ & Sex & & $\begin{array}{c}\text { Age median } \\
\text { (months) }\end{array}$ \\
\cline { 4 - 5 } & & & Male & Female & \\
\hline 1 & Terrier & $39(50)$ & 17 & 22 & 17 \\
2 & German shepherd & $13(16.7)$ & 9 & 4 & 15 \\
3 & Mixed breed & $10(12.8)$ & 6 & 4 & 13.5 \\
4 & Pekingese & $4(5.1)$ & 2 & 2 & 9.5 \\
5 & Shih Tzu & $4(5.1)$ & 2 & 2 & 10.25 \\
6 & Doberman & $3(3.8)$ & 2 & 1 & 9 \\
7 & Great Dane & $2(2.6)$ & 1 & 1 & 8.75 \\
8 & Chihuahua & $1(1.3)$ & 1 & 0 & 24 \\
9 & Poodle & $1(1.3)$ & 1 & 0 & 24 \\
10 & Bulldog & $1(1.3)$ & 0 & 1 & 4 \\
& Total & $78(100)$ & 41 & 37 & 15 \\
\hline
\end{tabular}

$41.6 \pm 0.11 \%$ with no correlation or with increasing age $(r=0.03)$. Also, $\mathrm{Hb}$ showed normal distribution $(12.78 \pm$ $3.21 \mathrm{~g} / \mathrm{dL})$. No significant difference was obtained between males and females ( $t$ test, $P=0.020)$. Hb levels increased slightly with increasing age $(r=0.26)$. In one sample (a 12-month female Terrier), $\mathrm{Hb} \mathrm{A}_{1}$ reached a minimum level of $96.2 \%$ while in others, 28 out of $78 \operatorname{dogs}(\sim 36 \%)$, it was composed of $100 \%$ total $\mathrm{Hb}$ and showed a slight increase with age $(r=0.26)$ whilst more than $75 \%$ of samples possess $98 \%$ or more (Fig. 3). On the other hand, 28 out of 78 blood samples showed no $\mathrm{Hb} \mathrm{A}_{2}$, and $69.2 \%$ had lower than $1 \%$. In one case, $\mathrm{Hb} \mathrm{\textrm {A } _ { 2 }}$ was lower than $2.9 \%$. In general, $\mathrm{Hb} \mathrm{\textrm {A } _ { 2 }}$ decreased slightly with age $(r=-0.27)$. Thirty-nine cases out of 78 showed $\mathrm{Hb} \mathrm{F}$, but only in one case did it exceed $2.3 \%$. $\mathrm{Hb} \mathrm{F}$ in $91 \%$ of all cases was below $1 \%$ of the total $\mathrm{Hb}$ and resembles what is seen in humans. $\mathrm{Hb} \mathrm{F}$ in the blood of all animals was slightly decreased with age $(r=-0.18)$.

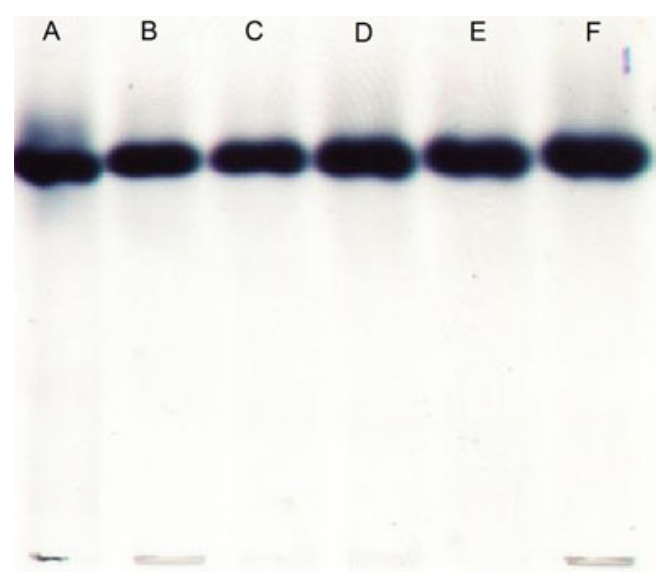

Fig. 1 Electrophoretic pattern of canine $\mathrm{Hb}$ on cellulose acetate. $A$ Male Great Dane, 1 year old; $B$ female mixed breed, 7 years old; $C$ Male mixed breed, 18 months old; $D$ male Terrier, 2 years old; $E$ female German shepherd, 3.5 years old; $F$ female Terrier, 2 years old. Note the Hbs approximately located in the same line
$\mathrm{Hb} \mathrm{A}, \mathrm{A}_{2}$ and $\mathrm{F}$ were not significantly different between sexes using the Mann-Whitney test (data not shown). Male and female did not show an age difference with other $\mathrm{Hb}$ types. Age distribution in male and female dogs was approximately the same. There were no statistically significant differences between male (41) and female (37) dogs among all the measured parameters.

\section{Discussion}

The present study showed canine $\mathrm{Hb}$ electrophoretic pattern on cellulose acetate paper strips. The electrophoresis analysis was performed using densitometer software where we assumed that the $\mathrm{Hb}$ components $\mathrm{A}_{1}$ and $\mathrm{A}_{2}$ were the same as human $\mathrm{Hb}$. The results indicate that $\mathrm{Hb} \mathrm{A}_{1}$ is the major $\mathrm{Hb}$ component, but $\mathrm{Hb} \mathrm{A}_{2}$ was detected at the

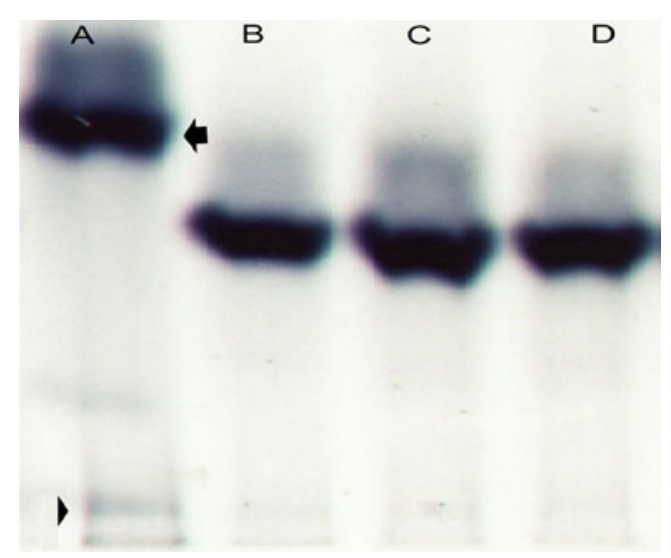

Fig. 2 Electrophoretic pattern of human and canine $\mathrm{Hb}$. A Male, human, 28 years old. The black arrow shows $\mathrm{Hb}$ type $\mathrm{A}_{1}$. The arrowhead indicates $\mathrm{HbA}_{2}$. $B$ Male German shepherd, 5 years old. $C$ Male Terrier, 1 year old. $D$ Female Terrier, 5 years old. Human $\mathrm{HbA}_{1}$ moved faster than canine $\mathrm{Hbs}$ 
Table 2 Distribution of different statistical measurements of $\mathrm{HCT}$ and $\mathrm{Hb}(\mathrm{A} 1, \mathrm{~A} 2$ and $\mathrm{F})$ in canine blood samples at the Small Animal Teaching Hospital, Veterinary School University of Tehran $(n=78)$

Corresponding $P$ values have been presented

${ }^{a} r$ Pearson correlation coefficient (between age and each parameter)

\begin{tabular}{|c|c|c|c|c|c|c|}
\hline \multirow[t]{2}{*}{ Parameter } & \multirow[t]{2}{*}{ Median } & \multicolumn{2}{|c|}{ Range } & \multirow[t]{2}{*}{ Mean \pm SD } & \multicolumn{2}{|c|}{ Correlation with age } \\
\hline & & Min & Max & & $r^{\mathrm{a}}$ & $P$ value \\
\hline Het $(\%)$ & 44 & 17 & 64 & $41.63 \pm 0.11$ & 0.03 & 0.789 \\
\hline $\mathrm{Hb}(\mathrm{g} / \mathrm{dL})$ & 12.5 & 5.3 & 20 & $12.78 \pm 3.21$ & 0.26 & 0.020 \\
\hline A1 $(\%)$ & 99.5 & 96.2 & 100 & $0.99 \pm 0.011$ & 0.26 & 0.022 \\
\hline A2 (\%) & 0.4 & 0 & 2.9 & $0.0067 \pm 0.0077$ & -0.27 & 0.016 \\
\hline $\mathrm{F}(\%)$ & 0.05 & 0 & 2.3 & $0.0031 \pm 0.0047$ & -0.18 & 0.114 \\
\hline
\end{tabular}

cathode side at minor levels in some dogs. Kitchen and Brett in 1974 claimed that canine adult $\mathrm{Hb}$ includes one or two types (Kitchen and Brett 2006). Electrophoretic pattern of 20 individuals of Canis familiaris, by Seal in 1969, showed only one $\mathrm{Hb} \mathrm{A}$ band and did not report any fetal $\mathrm{Hb}$ (Brimhall et al. 1977). It is interesting to note in our results that the curve obtained from canine $\mathrm{Hb} \mathrm{A}_{1}$ looks sharper than that of human $\mathrm{Hb} \mathrm{A}_{1}$ (Fig. 2). This indicates that canine $\mathrm{Hb} \mathrm{A}_{1}$ has greater homogeneity than human $\mathrm{A}_{1} \mathrm{Hb}$. Not only does the heterogeneity of $\mathrm{Hb}$ depend genetically on amino acid interchanges, but it could also originate from non-related genetic heterogeneity of $\mathrm{Hb}$, for example alteration of protein structure, i.e. $\beta$ chain $\mathrm{N}$-acetylation in feline $\mathrm{Hb} \mathrm{B}$ or glycosylation in diabetic dogs (Harvey 1997). Peptide sequencing of canine $\alpha$ and $\beta$ chains has described two kinds of $\alpha$ chains which differ with threonine and alanine at position 130 (Brimhall et al. 1977). In some samples, proteins like $\mathrm{Hb} F$ were seen between $\mathrm{Hb} \mathrm{A}_{1}$ and $\mathrm{A}_{2}$, but it was not significant in the present study. Three canine $\mathrm{Hb}$ phenotypes were observed by immobile isoelectric focusing in polyacrylamide gel technique in Braend's study (Braend 1988). The sensitivity of our technique is less than that of the polyacrylamide gel technique. Cellulose acetate electrophoresis is used as a routine screening technique for haemoglobinopathies, but agarose is the medium of choice because it can separate normal and more abnormal $\mathrm{Hb}$ easily and is commercially supported (Higgins et al. 2006). Considering the common heme structure of human and domestic animal $\mathrm{Hb}, \alpha$ - and non$\alpha$-chain amino acid sequences are responsible for electrophoretic differences in animals (Kaneko 2000). There are no reports of globin chain synthesis abnormalities in
Fig. $3 \mathrm{Hb}$ line graph. a Male dog, Terrier, 18 months old. b Female dog, mixed breed, 7 years old. There is no $\mathrm{Hb} \mathrm{\textrm {A } _ { 2 }}$ detectable by cellulose acetate electrophoresis in either male or female dogs. c Human, male, 28 years old. The major human $\mathrm{Hb}$ component is $\mathrm{Hb} \mathrm{A_{1 }}$ which is located at the anodal end, but at the cathodal side, $\mathrm{Hb} \mathrm{A}_{2}$ was seen, also. d Male dog. There is a trace amount of $\mathrm{Hb} \mathrm{A}_{2}$ at the cathode side in some of the dogs, similar to humans. In our study, a number of dog $\mathrm{Hb}$ patterns were like the human $\mathrm{Hb}$ pattern. It seems that the curve obtained from canine $\mathrm{Hb} \mathrm{A_{1 }}$ looks sharper than that of human $\mathrm{Hb} \mathrm{A}_{1}$. (Densitometer analysis is done by PhotoEP V7.51XP software)
A

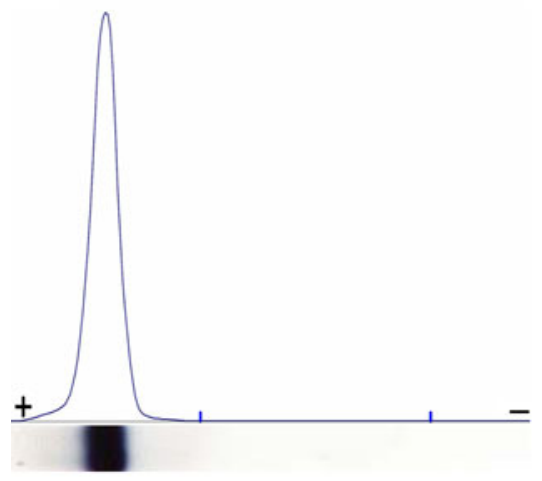

B

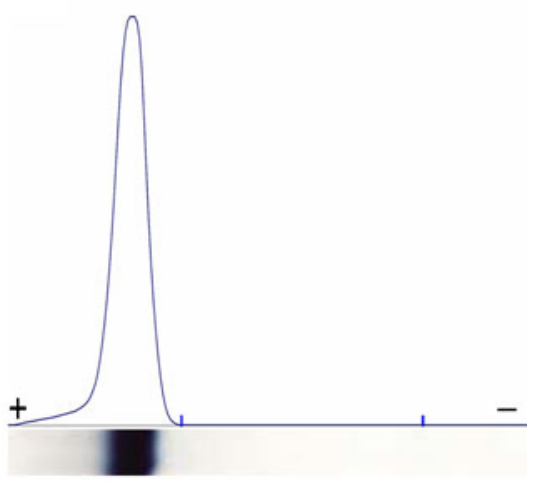

C

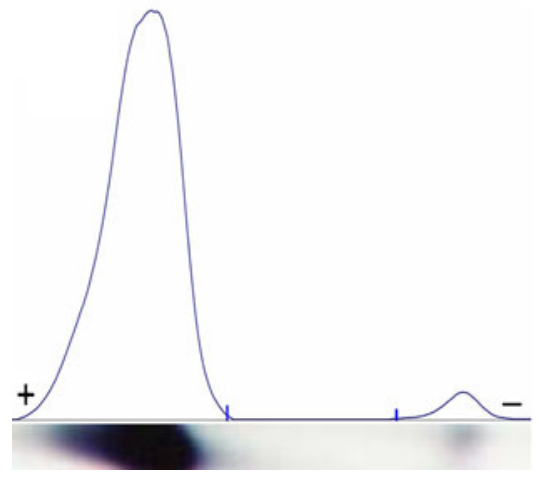

D

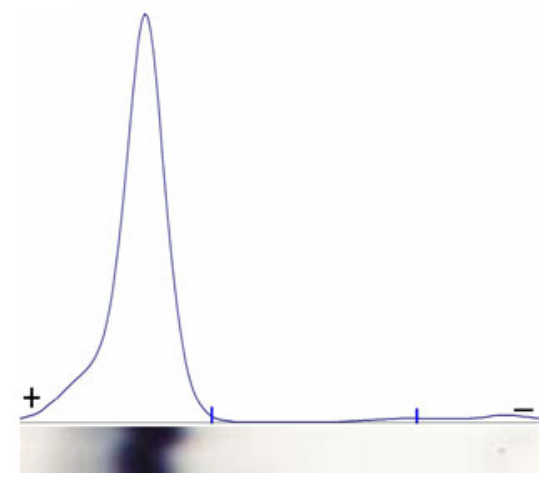


animals as seen in humans (Kaneko 2000; Broukus and Andreasen 2003). Therefore, globin charge and molecular weight are determined on electrophoretic pattern. Under alkaline condition, globin chains become negative. $\mathrm{Hb} \mathrm{A}_{1}$ yields more net negative charge and moves faster towards the cathode end. Normal $\mathrm{Hb} \mathrm{A}_{2}$ is closer to the anode end as a lower negative charge. We did not see any differences between electrophoretic patterns among canine breeds and sexes. It should also be noted that faster mobility has been discovered in human $\mathrm{Hb}$ in comparison to canine $\mathrm{Hb}$ on gel electrophoresis. The canine $\mathrm{Hb}$ subunits $\alpha(15,217.31$ molecular weight (MW), 141 amino acids, $\mathrm{PI}=7.98$ ) (UniProt: HBA_CANFA; available at: http://www.uniprot. org/uniprot/P60529, last modified July 21,1986$)$ and $\beta$ $(15,996.37$ MW, 146 amino acids, PI=7.96) (UniProt: HBB_CANFA; available at: http://www.uniprot.org/ uniprot/P60524, accessed February 19, 2010) are not that different from human $\mathrm{Hb} \propto(15,126.36 \mathrm{MW}, 142$ amino acids, PI=8.73) (UniProt: HBA_HUMAN; available at: http://www.uniprot.org/uniprot/P69905, accessed February $19,2010)$ and $\beta(15,867.22$ MW, 147 amino acids, $\mathrm{PI}=$ 6.81) (UniProt: HBB_HUMAN; available at: http://www. uniprot.org/uniprot/P68871, accessed February 19, 2010). Additionally, the average isoelectric point of canine and human $\mathrm{Hb}$ is 7.97 and 7.77, respectively. Therefore, it seems logical that the less PI a protein has, the greater the negative charge it will have and the faster it will move under $\mathrm{pH}$ conditions. In addition, human $\mathrm{Hb}$ molecules weigh less than canine $\mathrm{Hb}$, but as mentioned previously, because of the large pores in the cellulose acetate paper, the sieving effect is entirely dependent on net charge rather than molecular weight. In summary, we found that in canine species, $\mathrm{Hb} \mathrm{A}$ is the most important $\mathrm{Hb}$ component although in some cases, $\mathrm{Hb}_{2}$ was also found at the cathode end.

Acknowledgements The authors sincerely thank Mrs. Naderinejad and Ahmadzadeh for their special help and guidance.

Open Access This article is distributed under the terms of the Creative Commons Attribution Noncommercial License which permits any noncommercial use, distribution, and reproduction in any medium, provided the original author(s) and source are credited.

\section{References}

Bartlett R (1963) Rapid cellulose acetate electrophoresis: II. Qualitative and quantitative hemoglobin fractionation. Clin Chem 9:325

Braend M (1988) Hemoglobin polymorphism in the domestic dog. J Hered 79:21

Brimhall B, Duerst M, Jones R (1977) The amino acid sequence of dog (Canis familiaris) hemoglobin. J Mol Evol 9:231-235

Broukus CW, Andreasen CB (2003) Erythrocytes. In: Latimer KS, Mahaffey EA, Prasse KW (eds) Duncan \& Prasse's veterinary laboratory medicine clinical pathology, 4th edn. Blackwell Publishing, Ames, p 3

Elghetany MT (2007) Erythrocyte disorders. In: McPherson RA, Pincus MR (eds) Henry's clinical diagnosis and management laboratory methods, $21 \mathrm{st}$ edn. Elsevier Saunders, Philadelphia, P. 521

Harvey JW (1997) The erythrocyte: physiology, metabolism, and biochemical disorders. In: Kaneko JJ, Harvey JW, Bruss ML (eds) Clinical biochemistry of domestic animals, 5th edn. Academic Press, San Diego, Pp 162-163

Higgins T, Beulter E, Doumas BT (2006) Hemoglobin, iron, and bilirubin. In: Burtls CA, Ashwood ER, Bruns DE (eds) Tietz textbook of clinical chemistry and molecular diagnostics, 4th edn. Elsevier Saunders, Philadelphia, Pp 1172

Kaneko JJ (2000) Hemoglobin synthesis and destruction. In: Feldman BF, Zinki JG, Jain NC (eds) Schalm's veterinary hematology, 5th ed. Lippincott Williams \& Wilkins, Philadelphia. Pp. 137

Kitchen H, Brett I (2006) Embryonic and fetal hemoglobin in animals*. Ann N Y Acad Sci 241:653-671

Rosenbaum DL (1966) Hemoglobin electrophoresis on cellulose acetate. Am J Med Sci 252:130

Schneider R, Hosty T, Tomlin G, Atkins R (1974) Identification of hemoglobins and hemoglobinopathies by electrophoresis on cellulose acetate plates impregnated with citrate agar. Clin Chem 20:74

Telen MJ (2009) The mature erythrocyte. In: Greer JP, Foerster J, Rodgers GM (eds) Wintrobe's clinical hematology. 12th ed. Lippincott Williams \& Wilkins, Philadelphia. Pp 136-138

UniPro: HBB_CANFA. Available at: http://www.uniprot.org/uniprot/ P60524. Accessed February 19, 2010.

UniProt: HBA_CANFA. Available at: http://www.uniprot.org/uniprot/ P60529. Last modified July 21, 1986.

UniProt: HBA_HUMAN. Available at: http://www.uniprot.org/ uniprot/P69905. Accessed February 19, 2010.

UniProt: HBB_HUMAN. Available at: http://www.uniprot.org/uniprot/ P68871. Accessed February 19, 2010.

Westermeier R, Gronau S (2005) Electrophoresis in practice: a guide to methods and applications of DNA and protein separations. Wiley-VCH, Weinheim, Pp 13 